\title{
Quality Education for All? The Promises and Limitations of the SDG Framework for Inclusive Education and Students with Disabilities
}

\author{
Christopher J. Johnstone, Matthew J. Schuelka and Ghada Swadek
}

The Sustainable Development Goals (SDGs) reflect a contemporary vision for global development, building upon the successes and challenges of the Millennium Development Goals (MDGs) that expired in 2015. On a broad and conceptual level, the sDGs were set forth based on an agreed-upon global 'aim for a combination of economic development, environmental sustainability, and social inclusion' (Sachs, 2012, p. 2206). It was the first time that development goals integrated social, economic, and ecological dimensions within a singular framework (Griggs, 2013). The goals themselves were also developed differently as a result of a more broadly consultative process than the previous MDGs. Specifically, the SDGs were negotiated in open forum with civil society, advocacy, governmental, and scientific representatives present. This process differed from the MDG process, criticised for being overly focused on so-called 'expert opinion' and in which negotiations were conducted largely behind closed doors (Brown, 2016).

A key feature of the SDGs is the focus on the term 'inclusion'. The declaration and goals themselves contain 40 mentions of the word 'inclusive' ( UNGA, $2015 \mathrm{~b}$ ), yet the term is undefined. In most cases, the term refers to 'all' - all people who have the right to access the opportunities outlined in the goals. In this chapter we draw upon two recent conceptualisations of 'rights' and 'inclusion' as a way of understanding the evolution of these concepts from the MDGs to SDGs, and as a way to identify future directions for inclusive education in the SDG era, especially in relation to children with disabilities. For the remainder of the chapter, we outline the 'plural-relational' approach to inclusive education that draws upon legal and development scholarship to conceptualize inclusive education in the SDGs. 
The United Nations organisations call for inclusive education began in 1994 with the signing of the Salamanca Statement and Framework for Action on Special Needs Education. This declaration called for states parties to place greater emphasis on children with special educational needs (including children with disabilities) in national education systems. According to the Framework for Action, this could be achieved inclusively. In 2006, the Convention on the Rights of Persons with Disabilities (UN, 2006) reinforced this commitment, again calling for inclusive education for children with disabilities. Mégret (2008) noted that the more recent commitment, which specifically focused on persons with disabilities, was one of a long line of population-specific covenants that outlined the rights of groups such as ethnic minority groups, women, children, migrant workers, and indigenous populations. The naming of specific groups in UN covenants is described by Mégret (2008, p. 495) as the 'pluralisation of human rights'.

Pluralisation, according to Mégret, requires specific efforts to adapt the language of existing global human rights as well as acknowledge the unique experiences of groups that may require the creation of new rights. Mégret holds in tension the basic, common human rights shared by all as a normative ambition with the idea that 'human rights may also be about delving deeply into issues of identity, survival, and dignity of particular groups' (Mégret, 2008, p. 496). Referring to the tension between universal and plural rights, Mégret continued:

Even though the unity of rights captures a fundamental intuition, certain groups do need certain restatements of how rights apply to them, either because they have specific needs to enjoy their rights, different versions of the same rights, or possibly even slightly different rights. (Mégret, 2008, p. 497)

In sum, universal rights are those that may be enjoyed by all, a term frequently used in the universal sense in the MDGs. The SDGs, on the other hand, moved toward a more plural interpretation of rights, focusing on specific subgroups as target populations in discourse and for whom disaggregated data are expected in member state reports. For example, Indicator 4.5.1 requires that disabilitydisaggregated data be provided, to the extent possible, for all indicators. Thus, the rights of students with disabilities are conceptualised in the SDGs as a plural right. This population is subsumed under broader implications of 'all', but at the same time, disaggregation implies that this population may have particular 
educational needs that need to be closely monitored in national education systems.

At the same time, some of the data that are used to evaluate progress toward targets, in practice, may exclude children with disabilities. For example, targets 4.1 and 4.6 (focused on learning outcomes) will draw upon cross-national assessments, which structurally and conceptually exclude some students with disabilities (Brzyska, 2018; Schuelka, 2013a) or fail to provide appropriate accommodations. Despite limitations in data, the pluralisation of rights-based discourse in the SDGs represents a departure from the MDGs, which built upon calls for universal education. Pluralisation of educational rights, although logistically challenging in terms of evaluation, acknowledges the 'irreducible experiences of these groups in terms of rights' (Mégret, 2008, p. 498). The plural right to inclusion, then, is both concerned with the presence, participation, and achievement of all children and particularly with the educational needs of populations that have been historically marginalised (Ainscow and Miles, 2008). In the case of children with disabilities, a plural approach may begin to address the specific marginalisation of children with disabilities.

\section{Theorising Inclusion in the SDGs}

The pluralisation of the right to education represents a recognition of what data from both the Education for All process and the MDGs tell us - that improvements in educational access have occurred over the past three decades, but that marginalised populations remain marginalised within these mass movements. SDG 4 - in addition to naming plural rights, goes as far as identifying 'inclusion' as a solution to marginalisation, requiring nation states to 'ensure inclusive and equitable quality education and promote lifelong learning opportunities for all' (UNGA, 2015b, p. 17). The discourse of inclusive education has shifted over the past 20 years in Unesco. In 1994, the Salamanca Framework for Action called upon schools to 'accommodate all children regardless of their physical, intellectual, emotional, social, linguistic, or other conditions'. The focus on responsiveness toward children's 'conditions' has gradually evolved into a focus on the removal of organisational and pedagogical barriers. UNESCO's web resource on inclusive education at the time of the writing of this chapter 'promotes education systems that remove the barriers limiting the participation and achievement of all learners, respect diverse needs, abilities, and characteristics and that eliminate all forms of discrimination in the learning environment' (UNESCO, n.d.-a). 
Therefore, 'inclusive education' in the 21st century can be defined by two characteristics. First, it focuses on plural rights (Mégret, 2008), meaning that the concept of 'all' is held in tension with the acknowledgement that particular populations need specific attention because of historic exclusion from the benefits of universal rights. Second, inclusive education is characterised by a focus on systemic barriers that deny opportunities for presence, participation, and achievement in schools. In the context of SDG 4, metadata reporting requirements demand the evaluation of the implementation of plural rights, but these requirements face current challenges related to unavailable data.

The concept of inclusive education as a barrier-reducing activity is a challenge because, by its nature, it will require redistribution of resources, new thinking about how schools and curricula are designed, and fundamental questions about equity (differential resourcing of education in order to redress historic inequalities). The redistributive and transformative potential of inclusion and inclusive education, however, are equally challenged by interpretations of what the word means and how far states parties are willing to redress barriers. Sustainable development scholars Gupta and Vegelin (2016) define inclusion in economic and social terms, citing inclusion as a goal that requires structural change in how people participate in development and how scholars evaluate its outcomes. Gupta and Vegelin define 'inclusion' as

closing the income gap between the rich and poor, eliminating discriminatory laws and implementing social protection to enhance equality. This goes beyond social protection purely to prevent people from falling below the absolute poverty line. ... It tries to tackle structural inequality through changing decision-making processes, aid, investment, and trade agreements. (Gupta \& Vegelin, 2016, p. 442)

Gupta and Vegelin characterise inclusion in three ways: social inclusion, focused on participation of all in the sphere of development (Meier, 200o; Thorbecke, 2006); ecological inclusiveness, which focuses on development of ecocentric norms (Chambers and Conway, 1991); and relational inclusiveness, which focuses on issues of power and structural inequalities (Harriss-White, 2006; Mosse, 2010). Conceptualisation of inclusiveness and relevant examples are provided in Table 4.1. Gupta and Vegelin (2016) noted that only SDG 11, which focuses on inclusive and sustainable cities, met the authors' criteria for supporting all three types of inclusiveness. SDG 4 addresses both social and relational inclusion in its aims. Although some experts in inclusive education also promote inclusive schools as agents of ecological commitment (e.g., 
TABLE 4.1 Social, ecological, and relational inclusion in SDGS

\begin{tabular}{llll} 
SDG goal & Social inclusion & Ecological inclusion & Relational inclusion \\
\hline 1 & End poverty everywhere & $\begin{array}{l}\text { Resilience to } \\
\text { disasters }\end{array}$ & \\
2 & $\begin{array}{l}\text { End hunger/ } \\
\text { malnutrition }\end{array}$ & Sustainable agriculture & \\
3 & Enhance well-being & Tobacco convention \\
4 & Inclusive education & $\begin{array}{l}\text { Gender equality, } \\
\text { Outcome data } \\
\text { disaggregation }\end{array}$
\end{tabular}

\begin{tabular}{|c|c|c|c|}
\hline 5 & End inequality/sexes & & \\
\hline 6 & Universal access/water & Sustainable water mgmt. & \\
\hline 7 & Universal access/energy & Sustainable energy & \\
\hline 8 & $\begin{array}{l}\text { Employment for } \\
\text { all }\end{array}$ & $\begin{array}{l}\text { Enhance resource } \\
\text { efficiency }\end{array}$ & \\
\hline 9 & $\begin{array}{l}\text { Inclusive } \\
\text { industrialisation }\end{array}$ & $\begin{array}{l}\text { Sustainable } \\
\text { industrialisation }\end{array}$ & \\
\hline 10 & Reduce inequalities & & Reduce inequalities \\
\hline 11 & Inclusive cities & Sustainable cities & $\begin{array}{l}\text { Urban rural } \\
\text { interface }\end{array}$ \\
\hline 12 & & Sustainable consumption & $\begin{array}{l}\text { Control } \\
\text { privatisation }\end{array}$ \\
\hline 13 & & Combat climate change & Clim. Ch. Response ${ }^{a}$ \\
\hline 14 & & Sustainable marine life & Clim. Ch. Response ${ }^{a}$ \\
\hline 15 & Sustainable livelihoods & Sustainable ecosystems & \\
\hline 16 & Inclusive institutions & & Peaceful societies \\
\hline 17 & & & $\begin{array}{l}\text { Global partnership, } \\
\text { Disaggregated data }\end{array}$ \\
\hline
\end{tabular}

a Clim. Ch. Response refers to responsibilities of developed nations to address climate change.

b Sustainable marine life refers to both marine life and marine resources.

SOURCE: ADAPTED FROM GUPTA AND VEGELIN (2016)

Booth and Ainscow, 2016), the following paragraphs will examine social and relational inclusion examples found in the SDGs.

In terms of inclusion in education, the SDGs contain both social inclusion discourse (focus on the opportunities for participation in existing systems) 
and relational discourse (demonstrated by the frequent use of the term 'equitable'). Espinoza (2008) noted that educational proclamations (such as EFA, MDGS, and SDGs) frequently address equality of opportunity, meaning that students should not be discriminated against in their entry to school, but that once permitted to attend school, little is done to ensure equality of process, outputs, or outcomes. Antidiscrimination language, such as that found in the MDGs, focused on equality of opportunity.

The SDGs call for equitable education in both SDG 4 and Target 4.1. The term is also used several times in the resolution supporting the Agenda for Sustainable Development (UNGA, 2015b). Ensuring that students from marginalised groups can achieve similar results to their nonmarginalised peers requires dimensions of equitable resourcing and, more importantly, process and systems changes related to how schooling is done (Slee, 2013). Such resourcing will likely mean unequal resourcing, in favour of marginalised groups, such as children with disabilities or other special education needs (Johnstone et al., 2018). Although there is no blueprint for how states parties should consider differential resourcing in order to create inclusive systems, the acknowledgement that particular educational advantages may need to be redressed in order to promote inclusion aligns with Gupta and Vegelin's understanding of 'relational' inclusion.

'Plural-Relational' Inclusive Education

Our reading of the SDGs indicates that the goals are decidedly 'plural-relational' in their approach to inclusive education. SDG 4 aims to 'ensure inclusive and equitable quality education and promote lifelong learning for all' (emphasis added). One might, then, argue that every target and indicator has an inclusive education focus. In a majority of indicators - six, according to our analysis 'inclusive education' is indicated by identifying the specific rights of individuals more often than a broad aim of social inclusion for all. Language in targets and the metadata used to evaluate targets focus on identifying and addressing development gaps for particular populations who have been historically marginalised (Gupta \& Vegelin, 2016). Table 4.2 draws upon Mégret's (2008) and Gupta and Vegelin's (2016) work to illustrate the difference between a pluralrelational approach to inclusive education and one that could be characterised as universal-social models, which are often present in practice.

SDG 4 identifies pluralistic rights by naming girls, rural children, children from the bottom fifth wealth quintile in their countries, persons with disabilities, indigenous populations, conflict-affected children, students from 


\begin{tabular}{lll}
\hline & Universal-social & Plural-relational \\
\hline Population focus & All & $\begin{array}{l}\text { All, with particular focus on } \\
\text { historically marginalised }\end{array}$ \\
$\begin{array}{lll}\text { Equity/equality focus } \\
\text { Evaluative data }\end{array}$ & Equal opportunity & $\begin{array}{l}\text { Equity in process } \\
\text { Outcomes }\end{array}$ \\
\hline
\end{tabular}

developing countries, least developed countries, small island developing states, and African states as pluralistic rights bearers. Further, the disaggregated metadata for targets, coupled with calls for 'equity' imply that differential outcomes may trigger differential approaches, including new approaches to participation and performance in inclusive classrooms (UIS, 2018b).

For students with disabilities, a plural-relational approach to inclusive education represents a departure from previous educational proclamations. For example, Peters (2007) noted that the 2007 EFA global monitoring report hardly mentions children with disabilities. Anastasiou and Keller (2014) noted that a 'politics of silence' exists in the EFA discourse on disability and the education of individuals with disabilities, meaning that students with disabilities remain nameless in international discourse and ostensibly outside of what policymakers frame as 'all'. Anastasiou and Keller's cross-national study on special education - defined as educational opportunities for students with disabilities across settings; inclusive settings, resource classrooms, special schools - highlights the shortcomings of EFA approaches and implicates transnational governmental organisations for failing to recognise the educational needs of students with disabilities. The authors emphasise the lack of focus on disability as hindering the achievement of universal primary education, meaning access for all to early childhood education, literacy, and gender equity.

Miles and Singal (2010) reinforce the above critiques by first reviewing the history of EFA and its tendency to neglect children with special education needs. They further demonstrate that a tension has historically existed between EFA and inclusive education as a result of the lack of focus of EFA on particular populations, particularly children with disabilities. Furthermore, Miles and Singal suggest that the absence of individuals with disabilities from the EFA discourse is a result of a 'residual' notion that individuals with disabilities are uneducable, demonstrated by the continued presence of services in the ministries of health or ministries of social services of many counties 
(Miles \& Singal, 2010, p. 2). Advancing from EFA, MDG 2 was the primary goal addressing education, stating:

To ensure that, by the year 2015, children everywhere, boys and girls alike, will be able to complete a full course of primary schooling and that girls and boys will have equal access to all levels of education. (UN, 2000, p. 20)

EFA's original language, which specifically focussed on girls, provides an interesting model for further examining the rights of children with disabilities. EFA's specific mention of girls highlights a 'plural' right (Mégret, 2008), or a right that is population-specific because of historic inequalities. By naming girls, EFA noted that 'all' is intended to be every child, but that certain children need to be highlighted for the sake of unravelling legacies of exclusion. However, EFA and later MDG 2 stopped at the focus on gendered rights to education and missed an opportunity to outline further plural rights. Girls, for example, face cross-sectional exclusions that may include language, economic class, rural residence, and disability. Although in theory, focussing on every single child in the world, the de facto definition of 'all' throughout the EFA and MDG eras ended up meaning 'most'. With the exception of girls, both proclamations failed to recognise the interplay between universal rights for all children and specific plural rights that require discursive and policy focus. By focusing on the 'universal', specific focus on the marginalisation of persons with disabilities was almost entirely absent from the MDGs (Miles \& Singal, 2010). Furthermore, the synthesis of the United Nations' 2006 Convention on the Rights of Persons with Disabilities (CRPD) and the MDGs was recognised quite late in the MDG agenda (UN, 2011).

The plural-relational approach to inclusive education, specifically for children with disabilities, represents a new approach to inclusive education by the parties who negotiated the SDGs. The shift acknowledges that 'all' is a contested term and that in some places, particular children are considered ineducable or incapable of success in the classroom. The plural-relational approach to inclusive education for children with disabilities identifies the value of inclusive education, while at the same time recognising that this population may have unique rights and that those rights may need to be addressed through a critical examination of power structures and exclusion. At this point, the language is in place for a 2030 agenda of plural-relational inclusion, but the pragmatics of how to achieve such inclusion are still very much undetermined. The following section examines practical challenges of the plural-relational approach to inclusive education. 
Children with disabilities are more present than ever in international education goals, primarily through the SDGs' requirement of disaggregated participation and outcomes data. However, much of the data is not available at either national or international levels. Similarly, definitions of disability vary and are contested across societies. The Washington Group on Disability Statistics ${ }^{1}$ has made inroads on instrumentation, but measurement itself is an exercise in global diversity (for an example, see Sprunt, Hoq et al., 2017). Cappa, Petrowski, and Njelesani (2015) identified 716 instruments in 195 countries that are currently being used to evaluate children with disabilities. Data now are scattered, in places non-existent, and differ in degree of focus on functional, academic, and social outcomes (Cappa et al., 2015).

Plural rights and relational inclusion strategies also carry the risk of creating stigma, which has been a historic challenge for children with disabilities. Use of the label 'disability' in order to develop programmes, services, and supports may create 'special' programmes that stifle educational opportunities and contradict the premise of 'inclusive education' as articulated by CRPD and UNICEF. Although plural-relational inclusion represents an important innovation to population recognition and infrastructure of inclusive education, labels such as 'disability' may create prejudice or serve as a rationale for exclusion in practice.

Finally, the process of identifying marginalised populations raises new questions about who is not named as a plural-rights bearer or potential beneficiary of relational inclusion efforts. To this end, global initiatives such as the SDGs, their targets, and the metadata used to evaluate progress must remain flexible and in a state of constant renewal to ensure that inclusive development both pursues the benefits of all and recognises the particular rights and equity needs of those for whom traditional development approaches have not succeeded.

The plural-relational approach to inclusion found in the SDGs represents a particular approach to inclusiveness that was negotiated by participants in the framing of the 2030 agenda. The paragraphs above have presented the great potential for equitable inclusion that may be possible through this approach. The above sections also outlined challenges that are likely to emerge in practice. To provide context for both the opportunities and challenges presented in the 2030 agenda in relation to inclusive education for children with disabilities, 
we present two national case studies of Bhutan and Morocco in the pages that follow. These are sites for the ongoing research of Matthew Schuelka and Ghada Swadek, which is related to inclusive education and children with disabilities, respectively.

\subsection{Bhutan}

As a country in South Asia, nestled among the peaks of the Himalayas, Bhutan stands apart from its regional neighbours. As one of the last remaining independent 'Buddhist Kingdoms', Bhutan has been attempting to guide its development path through the Buddhist-inspired philosophy of Gross National Happiness (GNH). A rejection of economic growth 'at all costs', a GNH approach has guided Bhutan toward social and economic development at a cautious, careful, and sustainable pace, and to gradually embrace rights-based approaches to social institutions such as education. Bhutan is one of the few countries not only to reach its universal primary education and gender parity targets according to EFA, but to exceed them (UNESCO, 2015b).

Despite success in EFA access indicators, Bhutan continues to face serious challenges to the quality and inclusiveness of education. In his longitudinal and ethnographic study of inclusive education and disability in Bhutan, Schuelka (2013b, 2015, 2018) finds that sociocultural and institutional barriers in Bhutan prevent the kind of systems change necessary for quality inclusive education to flourish. The Bhutanese education system features a series of high-stakes examinations and a standardised curriculum that do not allow accommodation, modification, or differentiation. The sociocultural construction of schooling in Bhutan as an elite institution has led to the internationalisation by policymakers, school leaders, teachers, and, indeed, the students themselves, of the belief that only some children have the abilities needed to 'belong' in school (Schuelka, 2018). While Bhutan has initiated a progressive and rights-based approach to special education - the National Policy on Special Educational Needs - the policy is aspirational and does not address the everyday practices of teachers in facilitating an inclusive sense of belonging for all children in the classroom (Dorji \& Schuelka, 2016).

The factors and indicators of the inclusion of children with disabilities from gross enrolment to student-teacher ratios to achievement scores - only provide a two-dimensional understanding of the experience of inclusion. Just as Sprunt, Deppeler et al. (2017) argue in their study of Fiji, the SDG indicators advance a more complex way of understanding inclusion in schools, but more needs to be done with locally and contextually relevant indicators. None of the SDG indicators ask anything of the stakeholders themselves and only focus on 
things that can be numerically and summarily counted for the sake of global comparability.

Narrowing the understanding of inclusion by numerical indicators alone within the SDG is problematic, particularly in a country such as Bhutan. While Bhutan has made great strides in improving its gross enrolment primary education rate to $112 \%$ (Kingdom of Bhutan [KoB], MoE, 2015), it is the actual experience of the child in the classroom that makes education inclusive or exclusive. Schuelka (2018) found numerous instances of overcrowded Bhutanese classrooms where passive learning and nonparticipation were the norm (see also Kezang Sherab et al., 2015). Students with disabilities were 'there' physically, but their learning was not being supported in that the curriculum was static and the pedagogy was content-driven. Increased student attendance does not inherently lead to a higher-quality education, nor to better educational outcomes. In fact, increasing the number of students in the classroom has been found to have a detrimental effect on inclusion and educational quality for all students (UNESCO, 2015b). In Bhutan, this is certainly the case as more and more children have entered school, but the resources and teachers available have not sufficiently caught up to meet demand. Nearly $30 \%$ of students in Bhutan do not make it to grade 10, the end of basic education (KoB, MoE, 2015), which is perhaps a better indicator of inclusive education and demonstrates the limitations of access alone as an inclusion strategy. This is captured in the SDG 4 thematic indicators (4.1.1.c and 4.1.4), but only as an outcome and not necessarily as an indication of process and practice.

Disaggregating by disability - particularly as is the case with Indicator 4.5.1 - also comes with its own conceptual problems. Determining whether or not a child has a 'disability' is inherently embedded in sociocultural understandings of human difference and education as a social institution. Disability prevalence rates are notoriously erroneous and underreported (Groce \& Mont, 2017), although there has been an international effort led by the Washington Group to collect better disability data (Altman, 2016). At the national level in Bhutan, disability statistics are not collected in a sophisticated way, with even the GNH Index asking simple binary questions such as 'Do you have any of the following serious conditions, impairments or disabilities?' (Centre for Bhutan Studies and GNH Research, 2016, p. 305). This is conceptually problematic not only in Bhutan but for the SDGs as a whole, as every country will have differences in how disability data is collected and in how disability as a concept is perceived by both individuals and society.

In Bhutanese schools, many children are not labelled as being 'disabled', per se, but are otherwise struggling to cope with the curriculum and meeting learning objectives. Instead of being given a disability diagnosis 
and support services, these children in Bhutan are often called 'lazy' or 'slow' and left to their own devices to either overcome their learning difficulties through 'hard work and perseverance' or to fail out of the school system (Schuelka, 2018). A statistic that disaggregates by 'disability' will not solve this sociocultural issue of labelling children as 'lazy failures'. We are not advocating for a significant increase in disability labelling to occur in Bhutan or elsewhere; rather, we are highlighting the point that inclusive education is a systems approach that should affect the educational quality for all students, regardless of whether or not the institution has 'labelled' them. This is the dilemma attached to a plural-relational approach to inclusion, as argued above.

While nearly all of the SDG 4 indicators focus on macro-level statistics participation, access, number of years, financing, etc. - there was one indicator that tentatively explored the student experience in school: 4.a.2 - Percentage of students experiencing bullying, corporal punishment, harassment, violence, sexual discrimination, and abuse (UIS, 2018b). This indicator goes beyond simply acknowledging that students with disabilities are 'there' in the classroom and begins to look into the experiences of these students. In the case of Bhutan, 4.a.2 was an important indicator of the quality of inclusion for students with disabilities. Bullying, corporal punishment, harassment, violence, sexual discrimination, and abuse were all observed phenomena in Bhutan, despite official policies against them (Schuelka, 2015, 2018). However, it seems that Indicator 4.a.2 has recently changed, as the concepts were deemed too difficult to measure (Cornu \& Liu, 2018). The focus of the indicator is now on 'school violence' and narrowed only to bullying because it was methodologically easier to collect this data via a survey. A disaggregation of bullying data by disability is also not suggested (Cornu and Liu, 2018). This is a missed opportunity and indicative of how a data-driven and quantitative-indicator approach to inclusion narrows our understanding to input and outcome; rather than ecological, social, and relational inclusion (Gupta \& Vegelin, 2016).

While the Education 2030 Framework for Action supports country-level leadership in forming their own contextual indicators, the universalist message is still quite clear. In the Framework, UnEsco suggests, "The targets of SDG4-Education 2030 are specific and measurable, and contribute directly to achieving the overarching goal. They spell out a global level of ambition that should encourage countries to strive for accelerated progress' (WEF, 2015, p. 35). The national context of Bhutan suggests that the macro-scale of indicators may be too large to capture how inclusion is actually enacted in schools. Thus, we suggest that inclusive education that is specific to students with disabilities in Bhutan may be evaluated by: 
- amount of time students with and without additional learning support are together (disaggregated by curricular/noncurricular);

- ratio of trained teachers to students with additional learning support;

- amount of curricular time that students with additional learning support spend with teaching assistants and unpaid volunteers;

- curricular accommodation and modification available;

- percentage of students with additional learning support in the mainstream classroom; and

- number of students that transition to higher education or meaningful employment (disaggregated by disabled/nondisabled).

Of course, in suggesting this, there remains the conceptual issue of who is and is not a 'student with additional learning support' or in other words 'disabled'. The National Policy on Special Educational Needs (KoB, MoE, 2012, pp. 6-7) in Bhutan, which is still not settled legislation as of this writing, states:

A child has Special Educational Needs if he/she:

a Has a significant difficulty in performing any activity compared to the majority of children of the same age;

b Has a barrier which prevents or hinders her/him from making use of educational facilities of a kind generally provided for children of the same age in school;

c Is gifted;

$\mathrm{d}$ Is of school going age and falls within the definition given in $(a),(b)$ and $(c)$. This is essentially a functional definition, similar to the one used by UNICEF (2012) in conducting their Bhutan disability prevalence study, which found a prevalence rate of $21 \%$ among children aged $2-9$. As of now, officially there is no policy mechanism for determining whether or not a child in a Bhutanese classroom has a 'disability' as a catalyst to receiving additional or 'special' educational services. However, recent Bhutanese educational policy guidance advocates for an inclusive education for children with 'special educational needs' (KoB, MoE, 2018). We argue that this may be a blessing in disguise, as avoiding a medicalised or pathological approach to disability labelling can be more helpful in promoting a more dynamic, inclusive system where any student can move in and out of receiving additional learning support based on need, context, and situation. This assertion, however, challenges the 'universalist project of comparison and technical assistance ... to those who set themselves the task of producing statistics' (Ingstad \& Whyte, 2007, p. 12).

The case of Bhutan demonstrates that a rights-based inclusive education agenda, as measured by SDG indicators, may not capture how systems need to change in order for them to be considered truly inclusive. The SDGs call for 
equal access for children with disabilities, but in Bhutan, little is known about how inclusiveness occurs in classrooms as a matter of pedagogical and curricular practice. At the same time that Bhutan is emphasising educational access and inclusion, it also maintains a rigid, competitive, and high-stakes educational system that actively excludes and segregates children with disabilities - explicitly labelled or not. Further indicators suggested in this section, along with qualitative means of gathering information, particularly surrounding the student experience of being included in education, are intended to enhance the capacity of SDG 4 to promote inclusive education.

\subsection{Morocco}

Morocco is a lower-middle-income country continuing a multisectoral reform agenda set forth at the ascension to the throne of King Mohammed VI (World Bank, 2018b; Kingdom of Morocco [KoM], High Commissioner for Planning, 2015; KoM, 2012). Despite progress on the reform agenda, a persistent need for addressing the most vulnerable and marginalised populations, including children with disabilities, exists (UNESCO, 2014c). In the education sector, high student attrition and low literacy rates are pushing Morocco to embrace equityand quality-focused educational reforms to address these gaps (Ibourk, 2016; KoM, High Council for Education, Training, and Scientific Research [HCETSR], 2015; UNESCO, 2014C; USAID, 2013). SDG 4's focus on quality and inclusion parallels Morocco's current education needs. At the same time, a drive to produce graduates with marketable skills and the complexity of SDG 4's indicators have muddied the inclusion focus in Morocco (UIS, 2018e).

In order to address ongoing exclusionary practices, Morocco committed to the SDGs and their inclusive indicators. Morocco was one of the first countries to present a Voluntary National Review, which analysed current capacity to address the SDGs, to the High-Level Political Forum on Sustainable Development (HLPF), demonstrating its preliminary commitment to the goals (KoM, 2016). The discourse found in Morocco's Voluntary National Review repeats the notion of inclusion, stating, 'Public policies will focus on being ... more inclusive ... more equitable' (KoM, 2016, p. 7) and 'without exclusion' (KoM, 2016, p. 6). National and local implementation strategies also address inclusion, but mostly at the high-level policy, governance, or quantitative level (addressing the number of 'integration classrooms', teachers trained, assistant salaries paid) rather than addressing inclusive education quality (KoM, Ministry of National Education, Vocational Training, Scientific Research, and Higher Education [MNEVT], 2017a; KoM, MNEVT, Regional Academy for Education and Vocational Training, 2017; KoM, MNEVT, 2016a, 2016b). 
Some limited quality indicators have been included in educational plans at the national and regional level (supervisor/teacher trainings on specialised techniques for specific disabilities, curriculum design guides), but it is unknown whether they will be effectively implemented and evaluated for inclusionary practices (KoM, National Human Rights Council, 2015; KoM, MNEVT, Directorate of Curriculum, 2017a; KoM MNEVT, Regional Academy for Education and Vocational Training, 2017). Moreover, Morocco's financial and human resource capacity limitations hinder prospects for effective evaluation, monitoring, and data collection (Committee on the Rights of Persons with Disabilities, UN Human Rights Council [CRPD, UNHRC], 2015; KoM, 2016; Moroccan Press Agency Ecology, 2017).

In Morocco, like other low- and lower-middle-income contexts, the obstacles related to the education of marginalised populations have multisectoral root causes, ranging from lack of infrastructure, no access to prenatal and general health care, rural underdevelopment, and lack of social service capacity for linguistically diverse individuals (UNESCO, 2014c, 2018b). A variety of remedies have therefore been put in place across various ministries, government agencies, civil society, and international aid agencies, resulting in inefficient efforts and bureaucratic obstacles for those seeking support (CRPD UNHRC, 2015; UNESCO, 2014C; UNICEF, 2015). Consequently, 5\% of primary schoolaged children remain out of school, a large proportion of whom are children with disabilities located in urban, rural, or isolated regions of the country (UNESCO, 2014c).

One potential outcome of SDG 4 for children with disabilities in Morocco is that it will translate to meeting the access goals of the MDGs, but not necessarily the realisation of the intended 'quality' inclusive education. This is partly because Morocco's MDG experience demonstrates gaps at both the system and school level in implementation, data collection, and disaggregation, as related to marginalised populations in general and children with disabilities in particular. These gaps in foundational infrastructure for education at the systems, data, and implementation levels endure (Technical Cooperation Group [TCG], 2017; UIS, 2018c, 2018f; CRPD UNHRC, 2015; UNESCO, 2014C, 2018b). Under SDG 4, targets and indicators require new and more complex methodologies and data collection than during the MDG era. This creates feasibility obstacles for a country like Morocco that struggled to compile complete data for the MDGs (TCG, 2017; UIS, 2018c, 2018e, 2018f; CRPD UNHRC, 2015; UNESCO, 2014c; Cornu \& Liu, 2018). As a result, commitment to the SDGs may bring about improvements in access for diverse populations such as children with disabilities, but quality may still be out of reach. 
The reality in Morocco is that access to schools continues to be a great obstacle for many children with disabilities, despite constitutional protections, legislation, regional initiatives, and memoranda requiring registration (Myers, Pinnock, \& Suresh, 2017; UNESCO, 2014c, 2018b). Families often do not know or understand where to receive support, are unclear about their rights especially regarding education - face bureaucratic obstacles to school registration, and often must be put on waiting lists for limited spaces in centre- and school-based education programmes (Human Rights Watch [HRW], 2015; RTI International, 2016; CRPD UNHRC, 2015). Parents report that their children are often denied needed accommodations or forced to pay for supports their children require (HRW, 2015; RTI International, 2016). Historical disengagement by the Ministry of Education from meeting the needs of children with disabilities has resulted in nongovernmental organisations (NGOS) providing most services (HRW, 2015; RTI International, 2016). This situation does not provide for equitable or quality educational opportunities to and through education for children with disabilities as called for by CRPD and SDG targets 4.1, 4.5, and Indicator 4.a.1 (d) (HRW, 2015; RTI International, 2016; UIS, 2018e).

In an effort to move forward on inclusive education, the MNEVT, UNICEF, Humanity and Inclusion (formerly Handicap International), and the regional education authority partnered to conduct an evaluation and pilot programme in the Souss-Massa-Daraa region. The evaluation and pilot study found that major issues existed at the governance level, hindered by a lack of coordination between service sectors. These issues resulted in bottlenecks to schooling access, quality programmes, and financial budgets. The bottlenecks led to obstacles at the school level such as: a lack of communication and collaboration between centres and schools; school access that depended on the availability of trained teachers; a lack of specialised staff (medical and social); a lack of trained teachers in inclusive and adapted methods; and a lack of disability-friendly facilities and school transportation (UNICEF, 2014, 2015, 2016). UNICEF's evaluation also noted that attitudinal obstacles came from parents of children with and without disabilities and from teachers (UNICEF, 2014, 2016). These obstacles are those that plural-relational inclusion models seek to overcome.

Despite these challenges, evaluation of the pilot programme indicated positive results and has been used as the basis for the current national upscale of interventions for improving inclusive education. Results of the programme included: enrolment rates of children with disabilities increased to above $31 \%$; local governments earmarked funds for inclusive education (transportation to and from school); and improved coordination with health services. Furthermore, UNICEF's evaluation indicated that pedagogical changes were adopted 
and approved by the MNEVT to facilitate curricular accommodations for six categories of disabilities (UNICEF, 2014, 2016). The pilot programme achievements resulted in the Ministry of Education requiring inclusion inputs in national and local education plans and budgets, such as pedagogical training for teachers and individual student monitoring.

Additionally, in the spring of 2018, testing accommodations were put into practice on national end-of-year examinations for middle school certificates and high school graduation exams (KoM, MNEVT, 2018). And as of January 2019, The High Council for Education, Training, and Scientific Research conducted a conference on 'The Right to Inclusive Education: Conceptual Shift, Changes in Practice, and Evaluation Results', presenting the council's evaluation of the state of education for children with disabilities and its support for improving inclusive education (KoM, HCETSR, 2019). The following week, the Minister of Education formally met with NGOs working for the education of children with disabilities (KoM, MNEVT, 2019). This increased momentum could be indicative of a shift in the government's willingness to directly take responsibility for the education of children with disabilities within an inclusive framework.

The positive results referred to previously could potentially lead to improved engagement beyond the access aspect of SDG 4 toward a focus on quality. However, remnants of the MoE's past lack of responsibility for meaningful inclusion for children with disabilities continues to be evident through its publications. For example, the MNEVT Directorate of Curriculum, with the support of UNICEF, developed the Reference Framework for Curriculum Design for the Benefit of Children with Disabilities for six disability categories, which, at first glance, seem to address SDG 4.a.1 (d) (UNICEF, 2016; KoM, MNEVT Directorate of Curriculum, 2017b). Upon closer analysis, this reference document may actually create more barriers to access. The document limits curriculum accommodations to six categories of disabilities of 'mild to moderate degree' provided that a required medical report is submitted by families. Additionally, the Reference Framework reinforces the role of an initial medical committee review to 'advise' families on educational placement, which may be public schoolbased, public centre-based, or private school-based (KoM, MNEVT, Directorate of Curriculum, 2017b). Finally, although the guide is part of the reforms to transition from 'integration classrooms' (self-contained special education classrooms in public schools usually run by NGOs) to 'inclusion classrooms' for transition into general education, the three-year limit in the 'inclusion classrooms' to gain the necessary skills for general education may lead to student removal to more restrictive placements or student attrition (KoM, MNEVT Directorate of Curriculum, 2017b; RTI International, 2016). These aspects of 
the Reference Framework are exclusionary and demonstrate limitations to education not in the spirit of SD G 4.a.1 (d) due to a lack of prerequisite legal frameworks and education system safeguards for inclusive education as required by CRPD and recommended by Morocco's Human Rights Council (UN, 2006; KoM, NHR, 2015, p. 12).

Looking at these issues through another lens, both SDG 4 (4.4) and Moroccan educational policies demonstrate a tension between 'utilitarian' aspects of education (for students to be 'employable') and broader 'transformative' education (for the common social good or education for all) (Boutieri, 2016; Brissett \& Mitter, 2017). Through this confusion on the aims of education, a marginalisation of those who face barriers in attaining employable skills, such as children with disabilities, may occur. In such cases, the inclusionary vision of the SDGs, particularly tied to SDG 4, with education viewed as the key to 'leaving no one behind', may be trumped by the notion of 'relevant skills' for a global 21st-century economy (Brissett \& Mitter, 2017).

Finally, the realities of financing and the geopolitical consequences of conflicts in Africa and the Middle East and North Africa (MENA) region must be discussed in the analysis of the inclusive emphasis of SDG 4 within the Moroccan context. Morocco's National Review to the HLPF reported that 'the issue of financing for development was a major challenge for negotiations, during the process leading up to the 2030 Agenda for Development' (KoM, 2016, p. 10). Morocco's status as a lower-middle-income country with international loan debt, as well as dependence on development aid, positions it as insufficient to meet the SDG agenda (World Bank Group, 2018; Myers et al., 2017). This is especially true when looking at SDG 4's complexity and that the indicators 'require new methodologies, definitions and calculation methods, as well as considerable changes to national systems reporting data' (UIS, 2018e, p. 8), which Morocco has indicated it is too financially strapped to do (KoM, 2016). This renders the inclusive aspirations of SDG 4 potentially exclusive for implementation in low- or lower-middle-income contexts. Adding to these financial pressures, Morocco has hosted an increased number of refugees and migrants from the conflicts in the MENA and various African countries attempting to move to countries of the European Union, many of whom ultimately stay in Morocco. Refugees and migrants present other marginalised populations that must be educated in order to achieve SDG 4. These economic and political conditions must be addressed realistically in order for Morocco and other Global South countries to be 'included' in achieving the SDGs' mantra, 'leave no one behind'.

In conclusion, Morocco is a country in which a transition to inclusive education is emerging. However, Morocco first has to address the rights of those 
that were left behind during the MDG-era through a strategy that encompasses access, equity, and quality. As with other countries in the MENA, educational planning is based on quantitative data, such as the total number of integration classrooms, integration classrooms to be added per year, and schools upgraded for accessibility (Gaad, 2011; Hadidi \& Al Khateeb, 2015). Little research has been conducted and few data are available on educational effectiveness, educational considerations, and inclusive considerations most relevant to SDG 4's intention to promote equitable and quality inclusive education. As recommended for Bhutan, indicators that examine qualitative school/classroom processes and student experiences may be more useful to achieving equity and quality. The ultimate challenge for Morocco, however, may be meeting the financial obligations necessary to achieve SDG 4, without marginalising the most marginalised by prioritising education aimed at narrow visions of employability and responsiveness to market demands.

\subsection{Summary of the Case Studies}

The two case studies illustrate policy and practice at the national level. National examples (which include data from the lived classroom experiences of children) are important for two reasons. They provide a vantage point that informs broad global agendas and valuable information on the 'grain size' of national policy interventions. For example, in both Bhutan and Morocco, there appears to be a general acceptance of the plural rights of children with disabilities. At least in policy, there is a general acknowledgement of the contextualised rights that children with disabilities bear beyond those covered in universal declarations.

In both countries, however, this has historically translated into special systems of education for children with disabilities. Recent attempts at inclusion appear to align with Gupta and Vegelin's understanding of 'social inclusion' i.e., children with disabilities are present, but may not be experiencing quality education. Such quality requires policy commitments to equity and practices that are inclusive and that provide individualised support to those who need it most. Because these two activities have historically occurred in separate environments in Bhutan, Morocco, and most UN member states, the very localised practice of how to meet the 2030 agenda requires local innovations, targets, and solutions. As it stands now, outcome data on student learning is meant to hold member states accountable to their commitments but may not be enough to support local education professionals in creating cultures of inclusive education. To do this, localised qualitative and quantitative quality indicators are needed on the front lines of inclusive education. In time, such indicators may serve as complements to global disaggregated SDG metadata. 
SDG 4 represents a new era for inclusion and inclusive education. Inclusiveness is now characterised as both an acknowledgement of the unique rights of particular populations, while upholding universal rights, and a commitment to equity in education, which requires rethinking how education has always been approached by member states. In general, SDG 4 continues what was started with the MDGs by examining the outputs between sexes as a function of inclusion. However, the SDG targets and evaluative metadata are now placing greater emphasis on accountability for marginalised populations through examination of disaggregated data than ever before. As time passes, such data can be used to better understand what equity commitments need to be made on a global scale to ensure quality inclusive education for populations like children with disabilities.

In practice, such requirements will face challenges. Data collection and analysis can be expensive, the understanding of disability itself is highly localised and unstandardised, and global accountability measures have yet to catch up with new requirements. For example, universal design approaches to assessment, testing accommodations, and modifications are either non-existent or in a nascent stage for global instruments and in member states. Further, while the metadata are helpful for tracking global trends, further elaboration on what a high-quality inclusive education experience means is needed - and can possibly be accomplished through more qualitative and locally relevant indicators.

Despite these challenges, the 2030 agenda is bold in relation to inclusive education for children with disabilities. In this chapter, we have characterised the approach as plural-relational, drawing upon the human rights work of Mégret (2008) and the framing of inclusion by Gupta and Vegelin (2016). As with any global agenda, a great deal of work remains to be done at the national level and in local schools. However, three fundamental philosophical lines have been drawn by SDG 4. First, that the education of all means that special consideration must be made for those who have not historically benefited from mass educational movements. Second, because of this, equity of educational experience (rather than equality of opportunity) needs to be the focus of policy and resourcing. Finally, SDG 4 (as well as CRPD and other previous proclamations) has stated that these commitments are best accomplished through inclusive education.

\section{Note}

1 www.washingtongroup-disability.com 